\title{
Comparative analysis of the machined surface image after the process of burnishing rolling
}

\author{
A. Zawada-Tomkiewicz \& B. Storch \\ Koszalin University of Technology, Poland
}

\begin{abstract}
In this paper the machined surface after burnishing rolling was analyzed with the use of image data. The burnished surfaces were regarded as the post process after the turning. The effect of turning parameters on the machined surface image after the burnishing rolling process was demonstrated. The roughness peaks after burnishing rolling were flattened and the quality of the workpiece surface was improved. The surface texture after the burnishing rolling was indicated to be dependent on the previous process and possessed some features of turning. Surface images confirmed the complexity of all the stages of the manufacturing process forming the surface layer.
\end{abstract}

Keywords: burnishing rolling, machined surface, image analysis.

\section{Introduction}

The use of turning as a finishing process is often limited by surface quality requirements. Low roughness can be achieved only at low feed rates. Moreover, tool wear leads to deterioration in the surface [10-12]. A finishing operation can increase feed rates and prolong the tool life of the cutting tool.

Burnishing process offers an attractive post-machining alternative due to its chipless and relatively simple operations. Burnishing process is a cold working technique. Surface enhancement can be achieved by compressing the surface layer of the workpiece with a highly polished and hardened roller. When the applied burnishing pressure exceeds the yield strength of the material, the asperities of the surface will deform plastically and spread out permanently to fill the valleys $[1-3,5,6,8]$.

When combined with turning, burnishing rolling provides a manufacturing alternative to other finishing operations. The roughness peaks are flattened and 
the quality of the workpiece surface is improved. The surface is smoothed out and because of the plastic deformation the surface becomes work hardened, the material being left with a residual stress distribution that is compressive on the surface $[8,9]$.

The aim of the study was the investigation of the impact of the preparation of turned surfaces on the finishing process of burnishing rolling. The turned surface parameters and texture were indicated to determine the course of burnishing rolling and the burnished surface features. Optical imaging was used for burnished surface features identification and analysis. The machined surface images after burnishing rolling were compared taking into consideration the process before.

\section{Experimental procedure}

\subsection{Preparation of machined surfaces for burnishing rolling}

Nine turned surfaces were prepared for burnishing rolling. Cutting parameters were selected according to the tool manufacturer recommendations. Four constructions of cutting tool geometry were considered, which were described as wiper geometry, modified geometry and rounded tool nose featuring two different radii. More detailed analysis is described in [13].

\subsection{Burnishing rolling procedure}

Burnishing tools were designed for the purpose of experimental tests. Figure 1 shows a schematic representation of the burnishing tool mounted on the lathe machine TUB32. The head was mounted in a tool holder. The Rafan NUGH 14-27 head was equipped with three rollers. Each roller was built to possess the same features. It was $24 \mathrm{~mm}$ long with head entrance and exit featuring $2^{\circ}$ along $5 \mathrm{~mm}$ decrease $[7,8]$.

The workpiece was fastened in a three-jaw chuck. The burnishing parameters were selected according to the initial parameters of the machined surface after

a)



b)

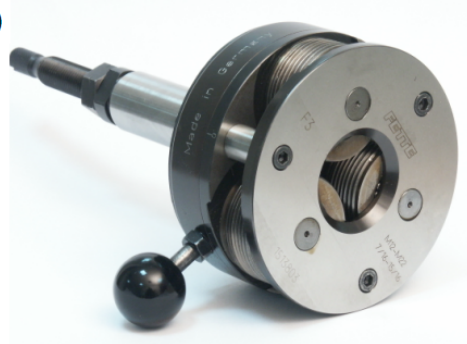

Figure 1: a) A photograph of the burnishing rolling tool and b) detailed view of the burnishing rolling tool assembly. 
the turning process. The three burnishing depths were chosen in dependence on the Rt parameter. It was accordingly $6 \mu \mathrm{m}, 8 \mu \mathrm{m}$ and $10 \mu \mathrm{m}$.

A calibration process was conducted and then the burnishing depth was set up. The feed rate in burnishing was forced in relation to the rotation angle of roller axis to workpiece axis. In this way the machined surface was burnished several times. It was multi-pass burnishing rolling.

Table 1: $\quad$ Summary of burnishing parameters.

\begin{tabular}{|c|c|}
\hline Burnishing rolling parameters & Values \\
\hline $\begin{array}{c}\text { Burnishing rotational speed } \\
(\mathrm{rev} / \mathrm{min})\end{array}$ & 14 \\
\hline $\begin{array}{l}\text { Burnishing initial diameter } \\
(\mathrm{mm})\end{array}$ & 25 \\
\hline Number of burnishing rollers & 3 \\
\hline Burnishing depth $(\mu \mathrm{m})$ & $6,8,10$ \\
\hline
\end{tabular}

\subsection{Surface roughness measurements}

Measurements of surface roughness were performed before and after burnishing rolling. The surface roughness was measured using the stylus method with the use of surface roughness HOMMELWERKE T2000E instrument. The cut-off and sampling lengths for each measurement were taken as $0.8 \mathrm{~mm}$. On each specimen, nine surface roughness measurements were made along the machined surface and an average of these values was taken as a response variable.

Burnishing process improved the surface roughness. For rounded cutting nose geometry the machined surface after turning was the result of kinematicgeometrical pass of the tool. The burnishing process smoothed the surface significantly to the mean roughness of $0.85 \mu \mathrm{m}$ when the burnishing depth was small.

For wiper tool geometry, additional radii smothered the traces after each pass of the turning tool. In this way the created machined surface only after turning was initially burnished. Applying burnishing rolling process for such a surface was in a way the repetition of the burnishing. The surface roughness parameters were only slightly smaller $(20 \%)$.

For modified turning tool geometry in a way of artificial wear the mean roughness of the machined surface after burnishing rolling decreased significantly $(60 \%)$. The machined surface after turning indicated the features of being reflective and very smooth. The burnishing process left these features unchanged. Still, after burnishing rolling only this surface was reflective and received the smallest value of Ra parameter $(0.61 \mu \mathrm{m})$.

The greater burnishing depths caused the change in surface roughness parameters. The change in feed rate from 0.2 to $0.3 \mathrm{~mm} / \mathrm{rev}$. caused the increase in surface roughness Ra parameter to be respectively $1.65 \mu \mathrm{m}$ and $1.85 \mu \mathrm{m}$. The maximum roughness was almost the same around $6 \mu \mathrm{m}$ for the Rt parameter and $4 \mu \mathrm{m}$ for the Rz parameter. 
a)



b)

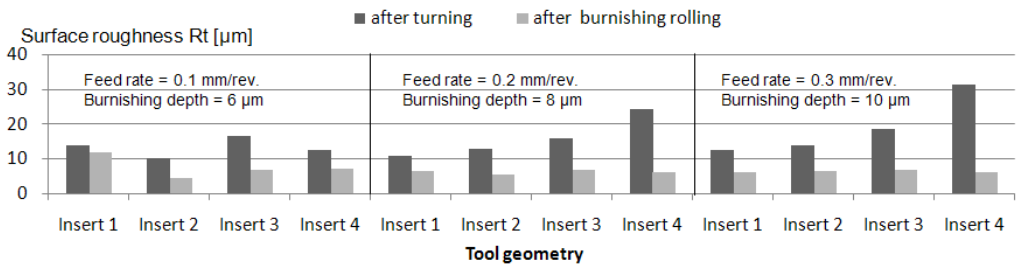

Figure 2: $\quad$ Surface roughness for the Ra and Rt parameters after turning and burnishing rolling for various tool geometries (Insert 1 - wiper geometry, Insert 2 - modified geometry, Insert 3 - rounded tool nose featuring $0.8 \mathrm{~mm}$ radius, Insert 4 - rounded tool nose featuring $0.4 \mathrm{~mm}$ radius).



Figure 3: Lighting configuration for the surface illumination. For burnished surface illumination two lighting systems were applied: two-sided lighting with the use of halogen - (1-3) and four-sided lighting with the use of halogen and LED - (1-2-3-4).

\section{Images of the machined surface after burnishing rolling}

The vision system for turned and burnished surface observation was based on a computer with a frame-grabber card, a digital camera, lenses, a stand for a camera with movable worktable and a lighting system (Figure 3).

Surface image observation needs the interpretation of colour. HLS model defines perceptual colour space by hue, lightness and saturation components [4]. Hue, dominant wavelength, defines the colour itself. Lightness, total power, 
indicates the level of illumination. Saturation, purity, indicates the degree to which the hue differs from a neutral grey.

Combination of HLS components in Figure 4 for rounded cutting tool featuring nose radius $0.4 \mathrm{~mm}$ and feed rate $0.3 \mathrm{~mm} / \mathrm{rev}$. enables the selection of images for the detailed analysis.
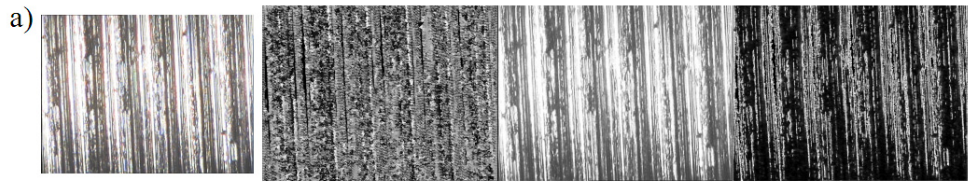

b)
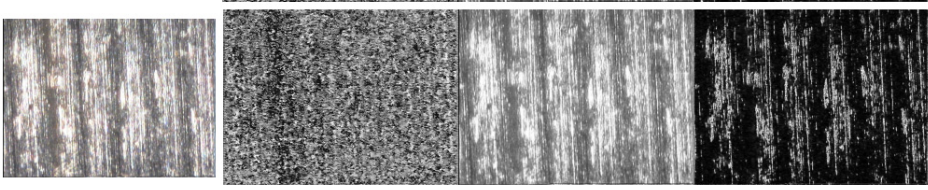

c)
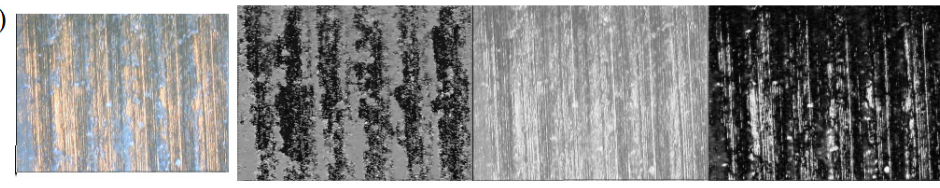

Figure 4: Machined surface image and its HLS representation: a) after turning with two-sided lighting; b) after burnishing rolling with two-sided lighting; c) after burnishing rolling with four-sided lighting.

The lightness component and the original image are very similar when printed out in gray. This component can be omitted in analysis. The hue component for two-sided lighting is omitted as well because it contains noise-like dispersed colour. Additional illumination caused ordering in a hue component. The interpretation of this component for four-sided lighting is covered by this paper. Saturation component is very similar for both ways of illumination and is discussed only for four-sided lighting.

\section{Analysis of the burnished surface images}

Images of machined surface after burnishing rolling, when illuminated with twosided lighting, show the features after the previous process, i.e. turning (Table 2). Feed rate and tool geometry can easily be indicated. Under this illumination the roll marks are also visible. The material plastic deformation process depends on the burnishing parameters. It is clear, however, that the initial state of the surface quality contributes to the final aspect of the part surface. The analysis highlights only the geometrical aspect of surface.

When the burnished surface is visualized under the two-sided lighting, then the feed marks are clearly visible. They are not as sharp as for turned surface but still recognizable. The texture of the image is blurred like after the low-pass 
filter. The images show several patches, which are light in colour. They testify to the levelling of the surface. These light spots are well lighted mirror surface parts which were particularly well burnished. Dark spots indicate the places on the surface where the penetration of light was difficult. They show the shadowed valleys after the tool pass in turning and pits left by cold-working burnishing.

Table 2: $\quad$ Machined surface image after burnishing rolling under two-sided lighting.

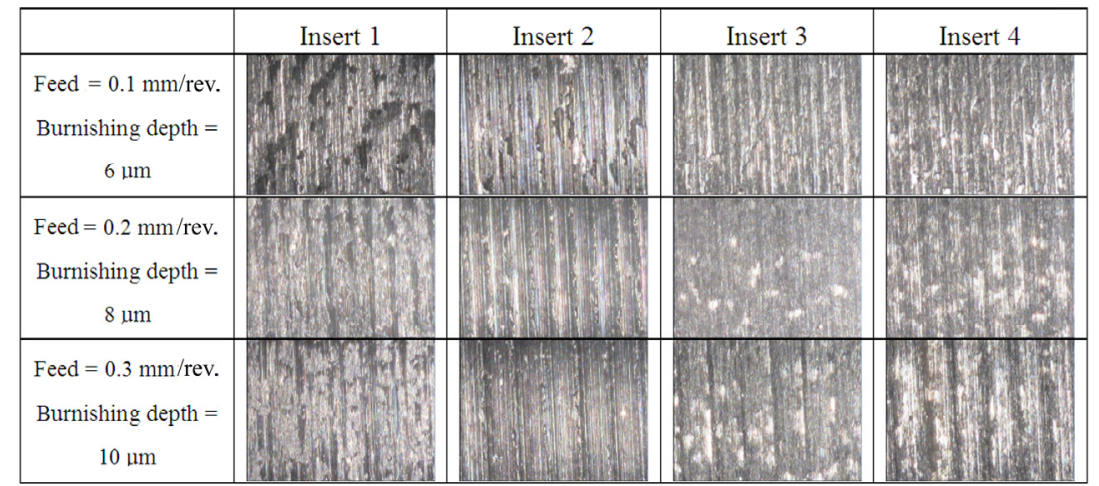

Table 3: $\quad$ Machined surface image after burnishing rolling under four-sided lighting.

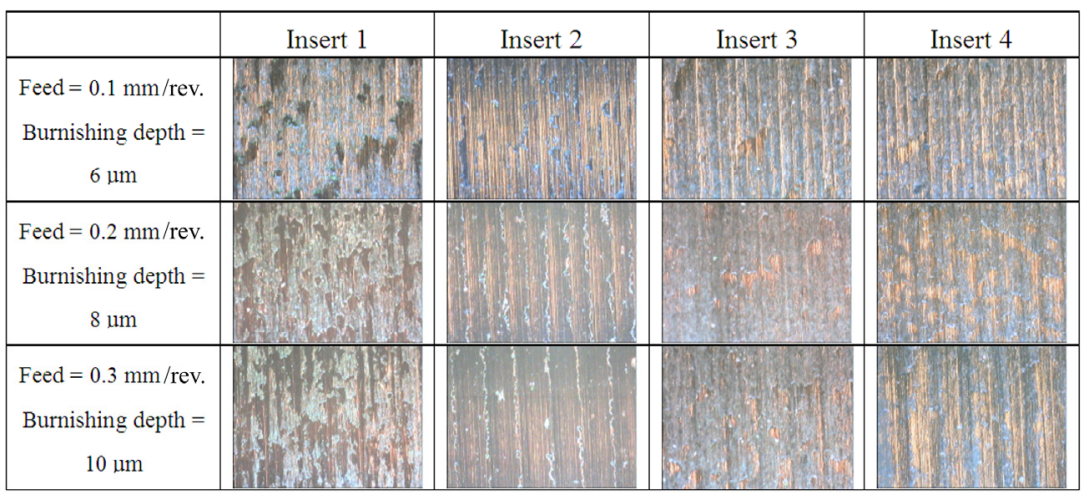

When the machined surface is illuminated by additional lightings located in such a way that the light penetrates the surface along the traces, then other features of burnished surface are revealed (Table 2). Under this illumination the feed marks are barely visible. The machined surface looks very flat.

The machined surface is distinctly different for the Wiper geometry. Pattern of developed dark and light spots is sharply outlined. For all feed rates, the light sheet covers the dark background. Randomly scattered dark pits point out at places where steel was not burnished. When the feed rate was smaller the dark 
spots were greater and the number of them was smaller. Increasing of feed rate caused the need of grater force and the depth of burnishing was greater. The number of pits was grater and their shape was more elongated. It is clearly visible the geometrical change of the machined surface in relation to turned surface.

For the modified geometry, the whole burned surface image is covered with fine dark points. When the feed rate is greater than for the machined surface after burnishing rolling the protruded rest of material along cutting traces is pressed. The groove interior is visible. The light is capable of penetrating the irregularities because they are not self shadowed and steep. Plastic burrs are sharply outlined. They occur periodically accordingly to feed rare value.

Table 4: $\quad$ Machined surface image after burnishing rolling under four-sided lighting - hue and saturation components.

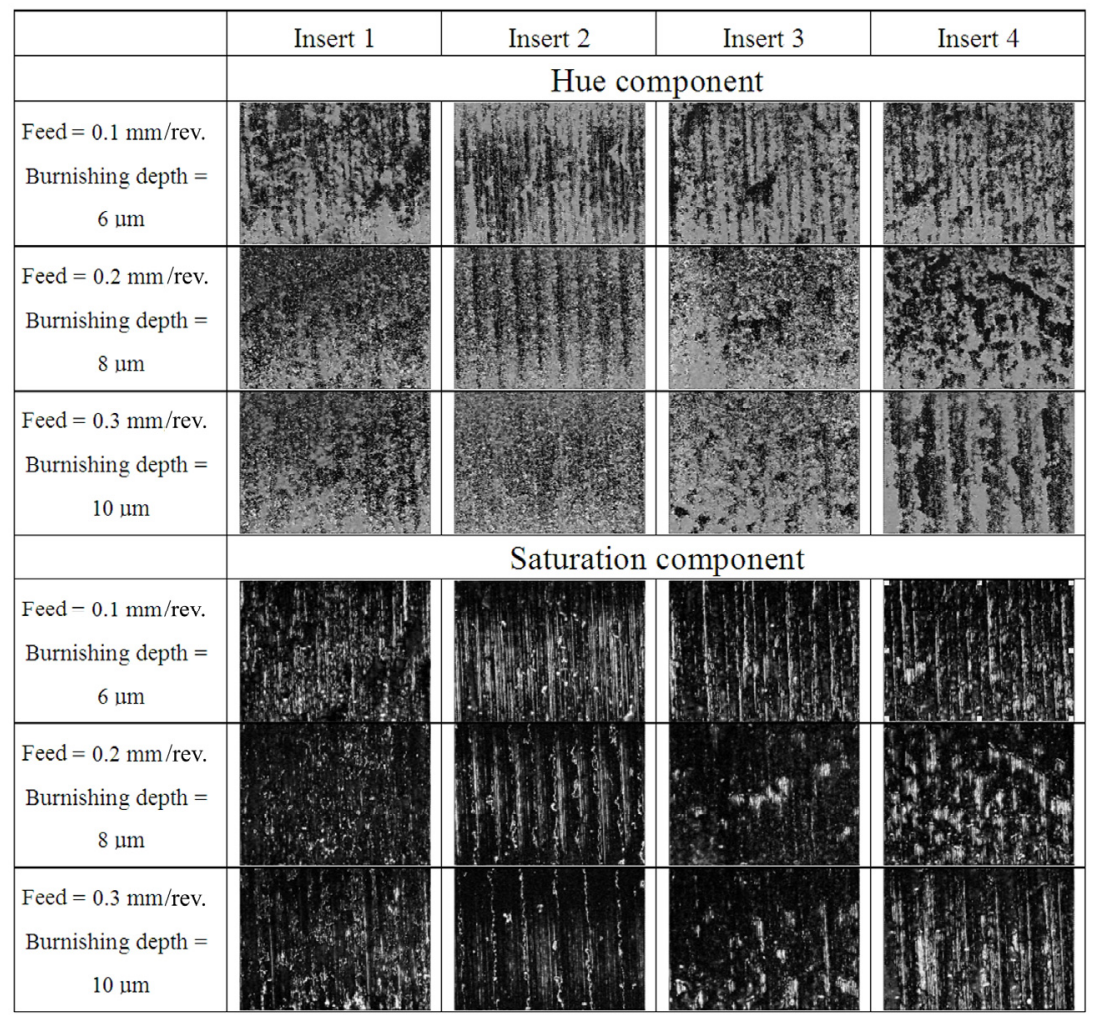

For the tool geometry in a shape of rounded cutting nose, the machined surface image after the process of burnishing rolling revealed the fine and uniform texture. Well distinguished plastically deformed surface fill most of the field of view. Plastically changed places stretch along the hills leaving 
undeformed material in valleys, on which the tool marks can be observed. It looks like as if the roller surface was spreading the material of the surface along the traces leaving some parts still untouched. Comparing the burnished surface with the turned one, gentler surface with blurred edges can be developed.

Analysis of colour components revealed additional features of burnished surface (Table 4). When the burnishing depth is small, then the distribution of colour (hue component) on the surface illuminated in the same way is similar. When the burnishing depth is greater, then the images show very different pattern of colour. For the modified tool, the small points create regular pattern. For wiper geometry the grey patches spread over an area of black and white noise. With increasing of burnishing depth the patches become less elongated and smaller. For rounded cutting tools, the hue component of the image underlines the irregularity of the burnished surface. Dark grey spots show the places when the changes in colour appear. When the burnishing depth and nose radius are greater, then regularity of the pattern is greater.

Saturation component shows how pure the colour is. White pixels indicate the places with colour. For wiper geometry, when the burnishing depth is small, then the dark image of saturation presents only threads and dots of colour. When the burnishing depth is greater than the threads are shorter and the dots are united. The image has more developed texture and in this way it can be described as being more colourful - contains more diversified fine patterns. For modified tool geometry, the increase of burnishing depth causes greater underline of undeformed material in a form of long white thin lines and more visible band of burrs. For rounded cutting tools the white threads are of different lengths but occur in feed rate interval. Increase of burnishing depth caused the increase of white thread lengths which often appear in groups.

\section{Final conclusions}

Burnishing rolling process caused for the turned surface to be more predictable in roughness parameters but very complex in image description. To simplify the task, the additional way of illumination of the surface was proposed with the consideration of colour components.

The proper illumination of the surface firstly was to reveal the features of turning parameters on the surface images after burnishing rolling and then to indicate the parts of machined surface still unchanged after burnishing and finally describe irregularities identified on the burnished surface image.

The effect of smoothing on the roughness peaks was described for a turned surface after burnishing rolling. A comparison between images of burnished surface was shown in Tables 1-3 when the same lighting conditions were preserved. The burnishing rolling has plastically deformed and removed the turning tool marks leading to smoother surface appearance. However, burnishing condensed the surface to a depth which was not sufficient to smooth out all the irregularities in the surface. 


\section{References}

[1] Ahmed R., Sutcliffe M.P.F., Identification of surface features on coldrolled stainless steel strip, Wear 244, pp. 60-70, 2000.

[2] El-Axir M.H., An investigation into roller burnishing, International Journal of Machine Tools \& Manufacture 40, pp. 1603-1617, 2000.

[3] El-Tayeb N.S.M., Low K.O., Brevern P.V., Influence of roller burnishing contact width and burnishing orientation on surface quality and tribological behaviour of Aluminium 6061, Journal of Materials Processing Technology 186, pp.272-278, 2007.

[4] Foley J.D., van Dam A., Feiner S.K., Computer Graphics-Principles and Practice, Addison-Wesley, 2nd edition, 1996.

[5] Klocke F., Liermann J., Roller Burnishing of Hard Turned Surfaces, International Journal of Machine Tools \& Manufacture 38, No 5-6, pp. 419-423, 1998.

[6] Korzynski M., Modelling and experimental validation of the force-surface roughness relation for smoothing burnishing with a spherical tool, International Journal of Machine Tools \& Manufacture 47, pp. 1956-1964, 2007.

[7] Kukielka L., The principals of engineering research (in Polish), PWN Warszawa 2002

[8] Patyk S., Patyk R., Kukiełka L., Problematic of parts technological quality forming in burnishing rolling process. Conference proceedings TON 2008.

[9] Sonka M., Hlavac V., Boyle R., Image processing, analysis and machine vision, PWS Publishing at Books/Cole Publishing Company, 1999.

[10] Storch B., The issues of edge phenomena and monitoring in single-point turning (in Polish), Technical University of Koszalin Press, Monograph 124, 2006.

[11] Zawada-Tomkiewicz A., Storch B., Classifying the wear of turning tools with neural networks, Journal of Materials Processing Technology 109, pp. 300-304, 2001.

[12] Zawada-Tomkiewicz A., Storch B. The Application of Image Processing Techniques in the Tool Wear Estimation, Computational Methods in Contact Mechanics VI, WITPRESS Southampton, pp. 201-210, 2003

[13] Zawada-Tomkiewicz A., Storch B. The analysis of the state of turned surface with the use of its image. Ninth International Conference on Surface Effects and Contact Mechanics Computational Methods and Experiments, WITPRESS Southampton, 2009 